\title{
Garbage Cans and the Hiring Process
}

\author{
Nikolaos Zahariadis, SUNY, College at New Paltz
}

"I t's crazy," "I don't understand it," "my condolences," "it's really tough out there"; these are all statements used to describe the process of getting hired at an academic institution. Most academics prefer to relate their experiences and give advice after they have been hired, but few profess to understand the process let alone predict who will be hired where. In the next few paragraphs I will first outline a model of decision making and then offer illustrative examples that seek to make sense out of the seemingly incomprehensible and potentially very disheartening process of getting placed at an academic, tenure track position. Unlike others, I want to relate this to other prospective job candidates while I am still a candidate myself, before my understanding of the process is "contaminated" by firsthand experience. My argument is that factors within and beyond a candidate's control shape the process, making it both promising and frustrating. The following is based on personal experience and reflection as well as information gathered from numerous interviewees at a variety of institutions.

My point of departure is Cohen, March, and Olsen's (1972) "garbage can" model of organizational choice. Since it was developed in specific reference to "organized anarchies," such as universities, it should be particularly appropriate to the task at hand. The authors postulate four streams flowing through an organization: problems, solutions, participants, and choice opportunities. Each stream obeys its own rules and flows independently of the others: budgets need to be passed, funds need to be cut (or enhanced), contracts must be signed, books need to be ordered. Decision outputs are heavily dependent upon coupling or joining together in whole or in part the various streams within a given choice context. In pure form, decision making is driven by the logic of timing - that is, when an opportunity arises to make a choice, the final decision depends on the particular mix of "garbage" in the can at any given moment. In reality the process is not random but rather structured by access and decision. Not every problem (access) or participant (decision) can be attached to every opportunity. Depending on the specifics of the situation some problems take precedence over others, while the composition of the decision-making committee (to the extent that one exists) varies across opportunities and over time. The key to understanding the process is coupling - that is, how a particular solution from a menu of solutions is attached to the problem of the day (assuming that only one solution can be attached to any given problem) by the decision makers of the day in a way that appears to be in congruence with the opportunity of the day.

So how does the model work in practice and how does it relate to the hiring process? The academic department is the organizational setting within which the hiring process takes place. There are courses to be taught, candidates to be hired, and committees that will do the actual hiring. A position announced in the APSA Personnel Newsletter, The Chronicle of Higher Education, or some other professional outlet signals the choice opportunity. The brief description of the position supplies a definition of the problem: there is a certain teaching need to be met. Of course not every faculty member defines this need in precisely the same way. Issues such as direction and strength of the department, fund availability, or affirmative action often shape the meaning of "need."

Concurrently, various solutions (candidates) make their appearance at different points in time. Every applicant is a teacher in search of a teaching need. There is of course no law that prohibits prospective candidates from applying to every advertised position, but time, mailing costs, and some common sense are good guides as to which positions might be more appropriate. Each candidate is equipped with different skills and can solve the same problem in different ways. Solutions and problems are dumped into the same "garbage can" by hiring committees, which are composed of faculty members under different time constraints and resources and each with his/her own agenda, definition of the problem, and image of the ideal candidate. The composition of committees obviously differs by position: a comparative politics search committee will surely look different from its American politics counterpart. As I will show later, the make-up of the committee makes a difference.

Committee members go through the files and select those who in their mind best meet departmental needs at that time. But the process of coupling, that is, finding a good "fit," is highly interactive in that departmental needs influence the selection of applicants as much as the pool of applicants helps define current needs. Consequently, the final output may be the selection of a candidate who fits a job description different from the one originally announced. The short list of candidates depends on a string of factors, some of which are beyond the applicant's control. Certainly merit-e.g. publications, conference presentations, good teaching evaluations-will get a candidate noticed. This is an element well within the applicant's control. There are, however, uncontrollable factors, from the candidate's point of view, that are also at work. The pool of applicants is important, for the candidate's chances of success depend on his/her competition at that time. Some pools are more limited than others and in certain 
years they tend to be more competitive. During the course of the search candidates drop out of certain "cans" to take positions elsewhere; so the pool is never static. Pedigree certainly features prominently here as well. It is a common secret that some professors prefer to look only at candidates from the "right" schools, say, their alma mater, certain Ivys, or the Big Ten. Others like to hire people who share similar theoretical or methodological perspectives. Still others push for candidates whom they know (candidates with the inside "scoop") or resist the inclusion of applicants who rank high on another professor's list because they dislike that individual. In rare occasions, positions will be advertised with a specific person in mind. Obviously, the composition of the committee makes a big difference because these are the people who usually come up with the short list; so an applicant may make it on the short list of some professors but if the latter are not directly involved in the search process, or if the search committee's chair does not look kindly upon outside "interference," the end result may not be favorable. It should be obvious by now that factors beyond a candidate's control feature prominently during this stage.

So, doesn't merit count for much? It does, but it exercises a primary influence only in the final round. It makes a difference largely at the interview stage when the list is narrowed down to, say, four candidates. But the search for fit is not over because there may be at least four definitions of the problem, which don't have to be terribly similar since more participants, usually faculty members from the entire department, enter the process during this stage. It is during this time when the research presentation or class lecture will reveal the actual level of skills candidates profess to have. This is the crucial moment of final coupling when skills, personality, and a heavy dose of luck will combine to put the whole package together. Each candidacy represents a slightly different mix of problem, solution, and participants and only one package will be finally accepted. And while there is a host of 'do's and don't's" out there, one piece of advice might aptly summarize them all: "do your thing, and do it well." Of course, the process does not end there because the candidate who will get the final offer may refuse it for a variety of reasons. So being next in line, something that applicants might not know, may not be that bad after all.

To summarize, using a garbage can model I presented a hiring process that appears to be time and structure bound. Although the explanation may merit notice for its own sake, for it makes sense out of a dynamic and fluid process where rationality is the exception rather than the rule, the big question still lingers on: so what? Is there a glimmer of hope or is this another academic exercise in futility? Even if I know what the process might look like, a prospective candidate will ask, can I do something about it? The answer is yes. Acquiring as much teaching experience as possible, publishing in major journals, participating in conferences, getting grants from prestigious foundations, being on the dissertation advisor's good side and hoping he/she is well-connected will certainly increase the appeal of one's candidacy. Having said that, however, it is also evident from my essay that a lot of serendipity and politics are involved, particularly in the initial stages of the hiring process. Based on this model, what predictions can the applicant make? Do the candidates that profess to know how the process actually works have an edge over the rest? This is surely the stuff that separates good analyses from the rest, but I must now return back to reality! Alas, I am still in search of a tenure track position, too!

\section{References}

Cohen, Michael D., James G. March, and Johan P. Olsen. 1972. "A Garbage Can Model of Organizational Choice." Administrative Science Quarterly 17:1-25.

\footnotetext{
About the Author

Nikolaos Zahariadis is currently a Visiting Assistant Professor of Political Science at SUNY, College at New Paltz. He is interested in issues of European political economy and comparative public policy, and his book, Markets, States, and Public Policy: Privatization in Britain and France, is being published by the University of Michigan Press. His articles have also appeared in Journal of Public Policy, Social Science Quarterly, and International Interactions.
} 